\title{
Tracing Megafauna Mobility in Beringia using Strontium Isoscapes
}

CLEMENT BATAILLE ${ }^{1}$, MATTHEW WOOLLER ${ }^{2}$, JULIETTE FUNCK ${ }^{2}$ AND JEFFREY RASIC ${ }^{3}$

${ }^{1}$ University of Ottawa

${ }^{2}$ University of Alaska Fairbanks, Fairbanks

${ }^{3}$ National Park Service

Presenting Author: cbataill@uOttawa.ca

Numerous paleoecological questions concern the mobility of ancient fauna in Beringia. Strontium (Sr) isotope ratio $\left({ }^{87} \mathrm{Sr} /{ }^{86} \mathrm{Sr}\right)$ analysis has emerged as a powerful tracer for determining the provenance of ancient biological materials. We measured the ${ }^{87} \mathrm{Sr} /{ }^{86} \mathrm{Sr}$ composition of teeth from present-day, herbivorous rodents $(n=162)$ sampled from across eastern Beringia to estimate bio-available ${ }^{87} \mathrm{Sr} /{ }^{86} \mathrm{Sr}$ values. We then used this dataset and a machine learning, random-forest regression to predict bio-available ${ }^{87} \mathrm{Sr} /{ }^{86} \mathrm{Sr}$ variations across eastern Beringia. We also develop a novel isoscape describing oxygen isotope values $\left(\delta^{18} \mathrm{O}\right)$ during the last glacial maximum. As a case study using our new ${ }^{87} \mathrm{Sr} /{ }^{86} \mathrm{Sr}$ isoscape, we measured the ${ }^{87} \mathrm{Sr} /{ }^{86} \mathrm{Sr}$ and $\delta^{18} \mathrm{O}$ of a series of radiocarbon-dated megafauna from eastern Beringia and compared these to our ${ }^{87} \mathrm{Sr} /{ }^{86} \mathrm{Sr}$ isoscape and a $\delta^{18} \mathrm{O}$ isoscape to estimate the probable landscape use of these ancient fauna. Our model and isoscape provide important foundations for a wide range of additional applications, including studies of the paleo-mobility of other fauna, ancient people and present-day fauna in eastern Beringia. 